\title{
Routine Is the Worst Enemy of the Dialysis Patients: Reply to Drs Basile and Casino
}

\author{
Charles Chazot Guillaume Jean \\ Néphrologie, NephroCare Tassin-Charcot, Sainte Foy Les Lyon, France
}

We deeply thank Dr. Basile and Dr. Casino for their interest in our opinion review regarding incremental dialysis. They disagree with our statement that the hemodialysis (HD) full start overweighs the benefits of incremental dialysis in incident patients. Thrice weekly chronic HD has emerged as the standard from the dialysis pioneers experience all along the first 10 years of practice. It was the era of enthusiasm regarding this new therapy treating a deadly condition, the era also of bedside clinical practice and common sense, not yet the era of evidence-based medicine. The still limited access of HD therapy at that time gives even more credit to the choice of thrice weekly HD as the standard. It is nowadays quite legitimate to challenge this standard because new data since then have

\section{References}

1 Hwang HS, Hong YA, Yoon HE, Chang YK, Kim SY, Kim YO, et al. Comparison of Clinical Outcome Between Twice-Weekly and Thrice-Weekly Hemodialysis in Patients With Residual Kidney Function. Medicine (Baltimore). 2016 Feb;95(7): e2767. pointed out the importance of residual kidney function (RKF). But the benefits of incremental dialysis start remain unproven. First, the better RKF preservation or noninferiority regarding outcomes has to be confirmed from randomized controlled trials (RCTs). During the writing of our review, only one RCT on incremental HD was recruiting. Since then several more have been registered on ClinicalTrials.gov. We are waiting for their results. Second, even cohort studies do not confirm that incremental dialysis reduces the usual early peak of mortality when HD is started. Third, one cohort study shows that when RKF is equivalent, mortality is more than 4 times higher with twice weekly when compared to thrice-weekly regimen [1]. And it is during the first months of HD that RKF is at its maximum even in thrice-weekly programs. Last but not least, because of warnings [2], the leading team pushing for incremental dialysis recommends a large panel of criteria to qualify for twice-weekly dialysis and to limit the risk of "underdialysis" [3]. This makes the incremental program not suitable for a significant number of patients. And beyond the RCTs, it is possible that a number of concerns summarized in Table of our paper [4] will remain unanswered. Then for us the time of incremental HD has not come yet. If RCTs favor incremental HD start in the future, then the implementation in a large scale will have to be strictly supervised to avoid underdialysis and the negative effect of routine of the chronic HD world, our meeting point with Drs Basile and Casino.
2 Obi Y, Streja E, Rhee CM, Ravel V, Amin AN, Cupisti A, et al. Incremental Hemodialysis, Residual Kidney Function, and Mortality Risk in Incident Dialysis Patients: A Cohort Study. Am J Kidney Dis. 2016 Aug;68(2):256-65.

3 Kalantar-Zadeh K, Crowley ST, Beddhu S, Chen JL, Daugirdas JT, Goldfarb DS, et al. Re- nal Replacement Therapy and Incremental Hemodialysis for Veterans with Advanced Chronic Kidney Disease. Semin Dial. 2017 May;30(3):251-61.

4 Chazot C, Jean G. End-Stage Kidney Patients Require Hemodialysis Therapy Full Start. Blood Purif. 2019;47(1-3):214-22.
KARGER

(c) 2019 S. Karger AG, Basel

E-Mail karger@karger.com

www.karger.com/bpu
Dr. Charles Chazot

Néphrologie, NephroCare Tassin-Charco

7 Avenue Marechal Foch

FR-69110 Sainte Foy Les Lyon (France)

E-Mail charles.chazot@fmc-ag.com 